\title{
«Sobre un libro de versos»: el primer manifiesto poético de Federico García Lorca
}

\author{
EUTIMTO MARTÍN \\ Universidad de Aix-en-Provence
}

En 1944 Antonio Gallego Morell dio a conocer en La Estafeta Literaria $\left(\mathrm{n} .{ }^{\circ} 16\right)$ un poema que bien puede considerarse como el primer manifiesto poético de Federico García Lorca. Lo escribió en un ejemplar de las Poesías Completas de Antonio Machado (Ediciones de la Residencia de Estudiantes) «sin respetar el pie de imprenta, ni el título, ni los derechos que marca la Ley, ni el copyright 1917» ${ }^{1}$.

Mucho más tarde, transcurridos casi cinco lustros, con ocasión de la exhumación de otro poema lorquiano, Gallego Morell vuelve sobre el tema:

El 7 de agosto de 1918 [García Lorca] firma un poema que traza con lápiz violeta sobre las primeras páginas de la edición de Poesías Completas de Antonio Machado que dio a la estampa la Residencia de Estudiantes, ejemplar que mi padre prestó a García Lorca y que éste lo devolvió con el mejor prólogo para los versos de Machado.

$Y$ en nota a pie de página añade:

A. G. M. «Cuando Federico leyó a Machado...», La Estafeta Literaria, 16, 1944, p. 25. 
Poseo en mi biblioteca el ejemplar de Machado con el poema autógrafo de García Lorca. Incomprensiblemente este poema se inserta en la edición de Obras completas del poeta (Madrid, Aguilar, 1966) bajo el título Este es el prólogo, que fue un título ocasional dado por mí al publicarlo por vez primera. Creo que el poema - que no tiene título dado por Lorca- debería incluirse bajo el enunciado $A$ las poesías completas de Antonio Machado. ${ }^{2}$

Así lo hizo Arturo del Hoyo, responsable de la edición Aguilar, y a partir de 1973, con este título, entre los corchetes de rigor, puede leerse en la sección Otros poemas sueltos.

Ahora bien, este poema póstumo de Lorca ni debe ser publicado en la versión dada a conocer por Gallego Morell, ni el título por él propuesto es actualmente necesario.

En efecto, en los archivos de la familia García Lorca figura un manuscrito de esta composición, fechado el 19 de agosto de 1918 y que, por consiguiente, anula el autógrafo anterior del 7 de agosto del mismo año. Más aún, el poeta le ha adjudicado un título preciso: Sobre un libro de versos. Lo transcribimos a continuación, añadiendo al final (tras las iniciales GM - Gallego Morell-) las variantes de la primera versión y, en cursiva, las tachaduras que hemos podido descifrar (bajo el texto que las ha reemplazado).

\section{Sobre un libro de versos}

Dejaría en el libro este toda mi alma.

Este libro que ha visto conmigo los paisajes

5 y vivido horas santas.

¿Qué pena de los libros que nos llenan las

de rosas y de estrellas manos

que se esfuman y pasan!

¿Qué tristeza tan honda es mirar los retablos

10 de dolores y penas

que un corazón levanta!

2 A. G. M., «El primer poema publicado por Federico García Lorca», Bulletin Hispanique, T. LXIX, 3-4 1967, p. 487. 
Ver pasar los espectros de vidas que se borran.

Ver al hombre desnudo

en pegaso sin alas.

15 Ver la Vida y la Muerte,

la síntesis del mundo, que en espacio profundo

se miran y se abrazan.

Un libro de poesías

20 es el Otoño muerto:

los versos son las hojas negras en tierras

[blancas.

Y la voz que lo lee

es el soplo del viento

que los hunde en los pechos

25 -entrañables distancias-

El poeta es un árbol

con frutos de tristeza

y con hojas marchitas

de llorar lo que ama.

30 El poeta es el medium

de la Naturaleza

que explica su grandeza

por medio de palabras.

El poeta comprende

35 todo lo incomprensible

y a cosas que se odian

él hermanas las llama.

Sabe que los senderos

son todos imposibles

$40 \mathrm{y}$ por eso en lo obscuro

va por ellos con calma.

En los libros de versos

entre rosas de sangre

van desfilando tristes y eternas caravanas

45 que hirieron al poeta

que lloraba en la tarde

rodeado y ceñido por sus propios fantasmas. 
Poesía es Amargura, miel celeste que mana

50 de un panal invisible que fabrican las almas.

Poesía es lo imposible hecho posible.

Arpa

55 que tiene en vez de cuerdas

corazones y llamas.

Poesía es la vida

que cruzamos con ansia

esperando al que lleve

60 sin rumbo nuestra barca.

Libros dulces de versos

son los astros que pasan

por el silencio mudo

al reino de la Nada

65 escribiendo en el cielo

sus estrofas de plata.

¡Oh, qué penas tan hondas

y nunca remediadas

los versos dolorosos

70 que los poetas cantan!

Como en el horizonte descanso las miradas, dejaría en el libro

este itoda mi alma! 
1-2 GM: Dejaría en este libro/toda mi alma.

6 GM: dos versos = ...libros/que... se esfuman $y$

$8 \quad$ que lentamente pasan!

9 GM: precedido de blancas separadoras, en dos versos = ...honda/Es...

11 GM: dos versos = ...espectros $/ \mathrm{de} . .$.

14 GM: En Pegaso sin alas,

15 GM: Ver la Vida y la Muerte

21 GM: dos versos $=$...hojas/negras...

22 GM: Los/lo

26 GM: no precedido de blancas separadoras.

30 GM: precedido de blancas separadoras.

40 GM: de noche/en lo obscuro

41 GM: en calma./con calma.

44 GM: dos versos = Van pasando las tristes/y eternas caravanas

45 GM: hicieron/hirieron ¿Errata?

46 GM: Cuando llora en las tardes

47 GM: dos versos $=$...ceñido/por...

48 GM: amargura,/amargura,

53-54 GM: un solo verso.

59 GM: lleva/llevo

silencio

63 por el cielo mudo

74 GM: sin signos de admiración.

Fecha: GM: 7 Agosto 1918 Precedida de firma: Federico García Lorca No seguida de mención de lugar.

Cabría pensar que antes de devolver el libro al padre del futuro rector de la Universidad de Granada, Lorca volvió a copiar la composición para no quedarse sin ella. Pero las modificaciones que introdujo no son tan importantes como para justificar un cambio de fecha. Como es sabido, una vez que el poema había alcanzado en su redacción la madurez deseada, el poeta lo fechaba, y aunque volviera a trabajar sobre él -e incluso a recopiarlo- no modificaba ya la fecha de nacimiento. $Y$ el cotejo de ambas versiones no arroja modificaciones sustanciales. Pensando sin duda en su publicación, el poeta lo peina métrica y tipográfi- 
camente para hacerlo presentable. La regularización en heptasílabos, simples o dobles, parece haber sido su propósito fundamental y hay que reconocerle el particular acierto expresivo del alargamiento en alejandrino del verso 44, lo mismo que el desgajamiento de Arpa del verso 54. La mejora técnica salta a la vista.

Antonio Gallego Morell -que en 1918 ni había nacido siquiera, se complace en imaginar una escritura directa sobre el libro de Machado:

Una tarde - precisamente la del 7 de agosto- se sentó allá en un banco albaicinero y sacó un lápiz morado - era el color y la tragedia de su vida-, con el que empezó a escribir sin levantar la mirada [ ... E Empezó a trazar versos con su letra de niño chico... ${ }^{3}$

No en el Albaicín sino en el mucho menos eufónico pueblo de Asquerosa (luego Valderrubio, que es donde la familia García Lorca pasaba entonces los veranos) compuso, pues, Lorca este poema.

Recordemos que en 1918 Federico García Lorca recibe el espaldarazo de escritor: es en la primavera de este año cuando publica su primer libro: Impresiones y paisajes. Pero Impresiones y paisajes no contiene más que prosa y el joven Federico quiere pasar a la posteridad como poeta. Hace ya más de un año que escribe versos (de junio de 1917 fecha su primer poema conservado) pero ni uno solo se ha decidido aún a dar a la imprenta. Francisco García Lorca cree recordar: «Debió ser en el año 1918 cuando mi hermano y yo decidimos ordenar los poemas escritos. Estaban en su mayor parte fechados y fue fácil numerarlos por orden cronológico» ${ }^{4}$.

Sobre un libro de versos aparece fechado pero no numerado. Una de dos: o bien no estaba escrito aún cuando los dos hermanos llevaron a cabo el ordenamiento cronológico, o bien no pudo numerarse por no llevar fecha. Nos inclinamos por esta última suposición. El 7 de agosto sobre el libro prestado puede que corresponda a la fecha de esta transcripción. Porque es difícil imaginar que el texto de Poesías completas de Machado sea una composición directa. Más lógico resulta suponer que Lorca pasa a limpio un borrador previo. De ahí el desbordamiento sobre el pie de imprenta, título, copyright etc, de un extenso poema de 79 versos para el que no se había previsto inicialmente tan estrecho so-

3 La Estafeta Literaria, loc. cit.

4 F. G. L., Federico y su mundo, Madrid, Alianza, 1981, p. 162. 
porte. Una vez transcrito el poema, lo fecha: 7 de agosto. Devuelve el libro a su propietario y se queda con el borrador del poema. Que sigue sin fecha.

Cuando le llega el turno a esta composición en el ordenamiento de la producción poética que Francisco está realizando (es él quien numera en el margen superior derecho de los originales) el poeta - a instancias, sin duda, de su hermano- ha de completarlo con título y fecha y seguramente pasarlo a limpio también. Se observa en el día de la fecha una vacilación por parte del autor del poema. Primero ha escrito: 7 de agosto (son perceptibles dos angulosidades en la parte superior e inferior del n. ${ }^{\circ} 9$ que corresponden al primitivo 7 luego rectificado en 9). A continuación ha colocado el 1 ante el 9 (la desnivelación del 1 con relación al 9 acusa una ejecución posterior). Ya sea que no está muy seguro de que se trate realmente de un 7 de agosto o, sencillamente que, habiendo cambiado el poema de configuración, opta por fechar la nueva transcripción, el caso es que, de ser cierta nuestra hipótesis, tendríamos la fecha de composición ( 7 de agosto) y la de revisión (19 de agosto). Precisión esta realmente insólita en la cronología poética lorquiana.

Pero ¿por qué le impone de este modo García Lorca a su amigo Gallego Burín las primicias de Sobre un libro de versos?

Aunque sólo tres años mayor que Lorca, el futuro alcalde de Granada gozaba ya, en 1918, de una reconocida autoridad intelectual. Tenía asombrados a sus paisanos desde que «a los catorce años empezó a publicar sus primeras colaboraciones periodísticas en la prensa local $\rangle^{5}$. En este agosto de 1918 estaba ultimando los preparativos para el lanzamiento de una ambiciosa revista: Renovación (Periódico regional, político y literario). En sus páginas recibiría el autor de Impresiones y paisajes su bautismo de poeta con la publicación, en diciembre del mismo año, de Crisantemos blancos (poema que está aún por exhumar) ${ }^{6}$. ¿Fue Sobre un libro de versos una especie de tarjeta de visita poética que le pasó Lorca a su amigo para que no lo olvidara a la hora de establecer la nómina de poetas de Renovación?

5 Ian Gibson, Federico García Lorca, Barcelona, Grijalbo, 1985, p. 138. De aquí tomamos todos los datos concernientes a Antonio Gallego Burín.

6 Igualmente en Renovación se publicó Granada (Elegía humilde) el primer poema hasta hoy aparecido de los publicados por Lorca (Cf. supra nota 2). 
Sobre un libro de versos no es una composición improvisada sobre el tomo de Poesías completas del famoso profesor del Instituto de Baeza. Desde que ha leído la Oración por Antonio Machado al frente de este libro sueña nuestro aprendiz de poeta con enmendarle la plana a Rubén Darío. Tres meses antes de devolverle el libro a Gallego Burín ya le ha dado la réplica al autor de Prosas profanas en un periódico literario de Granada:

\section{UN PRÓlOGO QUE PUDIERA SERVIR A MUCHOS LIBROS}

Un eco dulce de balada sentimental es en nuestro corazón la visión del crepúsculo. Brillan nuestras estrellas interiores al sentir la cálida caricia de Venus que tiembla tiernamente en el horizonte. Nuestra historia, sea larga o corta, la tenemos que sufrir. Y es grandemente doloroso pensar en nuestra vida que tendrá su florecimiento, que llegará a su apogeo y que morirá dulcemente en el otoño fatal...

El libro del crepúsculo nos abre sus páginas de borrachera melancólica y nosotros las leemos llenos de inquietud serena. Florecen los campos de amapolas...

¡Vamos a reír [con] la dulzura de la naturaleza!... y la enorme dulzura de la lucha... pero nos abismamos un poco en nosotros, es decir, interpretamos el libro genial que tenemos delante y... pensamos, ;qué triste es pensar!... Vemos un desdoblamiento imaginario de lo que habrá de venir y quisiéramos fundirnos con los azules nacarados de los fondos. Pasan por nuestra vista visiones admirables de la carne y del espíritu y nosotros sólo sabemos callar y sufrir ahogando nuestra sinceridad.

El poeta que es un personaje que debía ser sincero, se calla; en el fondo de su alma lo que quiere estallarle [¿es?] el corazón. Una sombra va a danzar en estas escenas llorando todo, lo triste y lo alegre.

Bien mirado, la alegría no existe, porque casi siempre en el fondo de los corazones se aposentó el dolor inmenso que flota en los ambientes del universo, el dolor de los dolores que es el dolor de existir. El poeta llorará estas escenas de verano con luna y rosales, escenas de crepúsculo de la naturaleza o del sentimiento.

Es la única oración que se puede hacer de verdad ${ }^{7}$.

En el fondo, es muy posible que el bisoño poeta hubiera preferido, como prólogo al libro de Machado, otro poema de Rubén Darío, Lo fatal:

Pues no hay dolor más grande que el dolor de ser vivo (el dolor de los dolores que es el dolor de existir)

7 Publicado por Antonina Rodrigo en Memoria de Granada: Manuel Angeles Ortiz. Federico García Lorca, Barcelona, Plaza y Janés, 1984, pp. 96-97, quien da la fuente: El Exito, Periódico quincenal literario, Granada, 10-V-1918.

Agradecemos a nuestra amiga el envío de una fotografía del artículo que nos ha permitido subsanar algunas incorrecciones en la transcripción. 
ni mayor pesadumbre que la vida consciente

(pero nos abismamos un poco en nosotros, es decir, interpretamos el libro genial que tenemos delante y pensamos, ¿qué triste es pensar!)

y el espanto seguro de estar mañana muerto

(y es grandemente doloroso pensar en nuestra vida $[\ldots]$ que morirá dulcemente en el otoño fatal)

y la carne que tienta con sus frescos racimos

(Brillan nuestras estrellas interiores al sentir la cálida caricia de Venus que tiembla tiernamente en el horizonte).

¿A quién sino a Rubén Darío mismo se dirige el flamante autor de Impresiones y paisajes cuando concluye, tajante: «Es la única oración que se puede hacer de verdad»?

Tanto Gallego Burín como García Lorca conocían ya, incluso personalmente, a Antonio Machado antes de la aparición, en julio de 1917, de sus Poesías completas. La visita al maestro en el Instituto General y Técnico de Baeza formaba parte de la asignatura de Teoría de la Literatura y de las Artes que en la Universidad de Granada les explicó su común profesor Martín Domínguez Berrueta ${ }^{8}$. Concretamente, en julio de 1916 - Gallego Burín dos años antes- el joven Federico le oyó recitar a Machado poesías suyas y de Rubén Darío. Habida cuenta de la presencia de Oración por Antonio Machado del nicaragüense en la cabecera de Poesías completas, constituía en cierto modo este recital un anticipo del libro.

Y del mismo modo que en 1917 Antonio Machado reivindicaba una filiación rubendariana colocando su poesía completa tras el poema Oración por Antonio Machado, el poeta novel Federico García Lorca se dispone, con Sobre un libro de versos, a caminar tras los pasos del autor de Campos de Castilla.

Al inscribirse en el registro de la poesía española, Federico García Lorca, pues, declara ser hijo de Antonio Machado y nieto de Rubén Darío.

Daniel Devoto primero, y Ian Gibson recientemente, ${ }^{9}$ han llamado ya la atención sobre la influencia de Rubén Dario en García Lorca.

8 Sobre el aprecio mutuo que se profesaban Domínguez Berrueta y Antonio Machado, cf. Ian Gibson, op. cit., p. 165.

9 D. Devoto, «García Lorca y Darío», Asomante, n. ${ }^{\circ} 2$, 1967, pp. 292-341. Ian Gibson, op. cit., cap. 9: «La juvenilia. Dios y Dionisos». 
De la presencia de Machado en la obra de nuestro poeta se ha señalado con frecuencia la impronta ${ }^{10}$ en la obra primeriza lorquiana. Parece en realidad mucho más duradera y profunda de lo que suele pretenderse.

Sobre un libro de versos vuelve a tener presente «Oración por Antonio Machado» pero ahora se desarrollan con especial atención dos versos precisos:

Montado en un raro Pegaso

un día al imposible fue,

que son corolario de otros dos precedentes:

Fuera pastor de mil leones

y de corderos a la vez.

Lorca, a su vez, que enraiza su quehacer poético en el rechazo de

Ver al hombre desnudo

en Pegaso sin alas,

propone como definición central de la poesía:

Poesía es lo imposible

hecho posible.

Arpa

que tiene en vez de cuerdas

corazones y llamas.

Porque, como ha dejado dicho anteriormente:

El poeta comprende

todo lo incomprensible

y a cosas que se odian

él hermanas las llama.

En este primer manifiesto poético de Federico García Lorca que constituye Sobre un libro de versos están tan presentes Rubén Darío como Antonio Machado. Y este último no por procuración:

10 Generalmente de manera vaga, sin llegar a un cuerpo a cuerpo de temas o poemas precisos. Por ello es de justicia señalar la honrosa excepción que constituye el artículo de José Manuel González Herrán: «Resonancias de Machado en el Libro de poemas de García Lorca», Peña Labra, 24-25, 1977, donde saca a cotejo los poemas Chopo muerto, Canción primaveral, Tarde y Meditación bajo la lluvia. 
¿Será tu corazón un arpa al viento, que tañe el viento? ... Sopla el odio y suena

tu corazón; sopla el amor y vibra... ${ }^{11}$

Pero Machado no ofrece una meta sino que echa en cara un reproche:

¡Lástima da tu corazón, poeta!

¿Serás acaso un histrión, un mimo

de mogigangas huecas?

Cierto es que en esta poesía la sombra narcisista de Unamuno (a quien va dedicado el poema) se proyecta sobre estos versos machadianos. Pero Lorca demuestra estar ojo avizor en sus comienzos. Tanto más atento a su propia voz cuanto que se siente irresistiblemente atraido a la órbita poética de Machado. Sobre todo tras la lectura de sus Poesías completas. De diciembre de 1917 fecha este poema que se diría un grosero remedo del autor de Campos de Castilla:

\footnotetext{
Tarde de Julio. Carretera polvorienta.

Un pueblo quieto [...]

La noria suena clara. La tarde declina.

El viejo señor cura da su paseo diario

con la roja sombrilla leyendo el breviario.

Los niños en la escuela cantan la doctrina.

Carros que van y vienen con aire muy lento.

Un vejete apagado marcha soñoliento [...]

Tarde brumosa de Julio. Un pueblo quieto ${ }^{12}$.
}

Esta composición no pasó a formar parte de Libro de poemas aunque fue fechada (30 de diciembre 1917) y numerada. Se comprende muy bien por qué.

¿Terminó el influjo de Antonio Machado sobre Lorca en Libro de poemas? Sería muy arriesgado afirmarlo. Sólo un cotejo minucioso de ambas obras poéticas podría responder correctamente a esta pregunta. En nuestra opinión, no. Hay ecos machadianos totalmente inesperados en la obra de Lorca. Por ejemplo, en la acotación escénica del Cuadro primero de El Público: «Decorado azul. Una gran mano impresa en la pared. Las ventanas son radiografías». ¿Visión surrealista? No mucho más acentuada que esta otra:

11 Luz. De Primeras poesías (O. Completas, Losada, p. 27).

12 Impresión. Poema inédito en los archivos familares del poeta. 
La tarde está cayendo frente a los caserones de la ancha plaza en sueños. Relucen las vidrieras con ecos mortecinos de sol. En los balcones hay formas que parecen confusas calaveras. ${ }^{13}$

Y es que, tratándose de Lorca, siempre:

Bueno es recordar

las palabras viejas

que han de volver a sonar.

13 Poema XCIV de Soledades. 